\title{
Research and Practice Based on Regional Planning and Design of Guangfu Landscape village__ A case study of YanQian village in Zhaoqing
}

\author{
Zhang Hong \\ College of Life Sciences, ZhaoQing University, Guangdong 526061
}

keyword: Qixing Rock Scenic area, marginal villages, Landscape Planning and Design, GuangFu Landscape village, productive Landscape

Abstract: Under the background of new rural construction, how to create a characteristic landscape village is an important research topic in the practice of landscape village construction. Zhaoqing Qixingyan Scenic Area is a famous scenic spot in the country, but the villages on the edge of it are long-term and chaotic. In recent years, in the landscape planning and design and renovation of the new project in Yanqian Village, combined with the characteristics of the village, the historical humanities and the location of the city center, the spatial pattern of one park, two streets, multiple lanes and many scenic spots was sorted out, emphasizing from the macroscopic The three levels of meso, meso and micro are comprehensively upgraded to create a transformation plan for Lingnan characteristic landscape villages that are livable, happy, and suitable for travel. After implementation, they have achieved very good results and can be used for similar planning and design.

\section{Scenic of village and "Village Image"}

Scenic village is a special type in the rural landscape. Its scope refers to the village area outside the scenic area, which is influenced by the scenic spot and part of it is also the scenic spot. It has the dual attributes of "Scenic" and "village" and is the middle zone between the scenic spot and the rural area. . With the development of scenic spots, Scenic village is the most vulnerable to scenic spots and is the most active village. Therefore, the heterogeneous nature of Scenic village determines its complexity, is the most active rural landscape belt, and is the most ecologically fragile.

With the development of rural tourism, the rural landscape has undergone amazing changes, especially the Landscape village next to the famous scenic spot. The rise of rural tourism not only promotes the change of rural landscape, but also promotes rural environmental governance, diversification of industries, improvement of villagers' quality of life, and improvement of rural living environment.

According to the identifiable "city image" planning and design proposed by American urban planning and design expert Kevin Lynch, Xiong 1 Kai of Wuhan University proposed rural imagery, 
and rural imagery is divided into rural landscape imagery and rural cultural imagery ${ }^{[1]}$. The image of the rural landscape is mainly composed of the village environment, the local architecture and the village settlement. The rural landscape image reflects the location of the village, the living and living methods of the villagers and the development of the village. The image of the rural landscape is unique, which also becomes a symbol of distinguishing other villages. This iconic symbol is the impression of the countryside that the rural landscape gives people.The image of rural culture is the core of the rural spirit, which is expressed as some villages.

\section{The Design method of Landscape village}

The construction of Landscape village should firstly organize the image of Jingcun, analyze the source of scenery, excavate the unique rural image of Jingcun, form symbolic features, and strengthen the symbolic features of this rural image in Landscape village design.Landscape village is attached to a large-scale scenic spot, and its development is dynamic. It must be clearly positioned to develop into a livable village with livability, suitable travel, suitable industry, and Yiwen, with distinctive characteristics and sustainable development.

The shaping of Landscape village needs to refine the imagery elements of Landscape village and the cultural imagery of Landscape village. The image elements of landscape village include the location relationship between Jing and Village, the spatial structure relationship of landscape village,

the architectural style, the ancient tree and other physical landscape elements; the cultural image elements of landscape village also include the customs of landscape village, production relations, folk allusions, clan relations. Such as cultural elements, to refine and use them.

The focus of the construction of the landscape village landscape is to rely on the resources of the scenic spot and focus on the creation of the landscape space of landscape village. landscape village is the link between the landscape elements and the landscape resources that are formed by the favorable terrain for a long time. It is the most effective way to show the image of landscape village.

\section{Design practice of Landscape village: planning and Design of Inkstone King Village}

Guangfu landscape village refers to landscape villages around the famous scenic spots such as Zhaoqing Xinghu Scenic Area, such as Yanqian Village, Qinglian Village, Shipai Lion Village, and Yitou Village. Their common point is that they have good scenery resources and Have the attributes of the village. On the one hand, they have been disorderly built and disordered for a long time, and they have seriously affected the scenery of the landscape. On the other hand, they have stayed on the surface of shallow sightseeing, and have not actually combed the appropriate development context and economic structure, and even brought homogenization. Many problems such as the destruction of the original life and the loss of traditional folk crafts, etc., how to adapt to the current environment and sustainable development is a major issue. The Yanqian Village on the edge of the Qixingyan Scenic Area belongs to such a village. This paper takes the landscape reconstruction of Yanqian Village as an example to explore the landscape planning design and innovation of the rural areas at the edge of the scenic area.

\subsection{Image combing of King Village}

Founded in the Tang and Song Dynasties, Yanqian Village has a history of thousands of years. It is located on the west side of the south gate of thefamous Qixingyan Scenic Spot in Zhaoqing. It is 
a peninsula with an area of about 1.5 square kilometers. It is located in one of the five major lakes in Xinghu Scenic Area. The shore of Lianhu Lake is an important tourist spot and tourist service area of Xinghu Scenic Area, with unique human and natural scenery . The original inhabitants living in the village are mainly Liu and Liang. The clan prints are distinct. There are more than 70 ancient buildings in the Ming and Qing Dynasties. There are more ancient trees, including 2 trees over 400 years old. 8 heads of folk traditional festivals (she), such as Tuanshe, Qingning Head Society, Near Star Society, Anhuai Society, Juying Society, and Kangning Zhengshe; the community has 6 joint-stock cooperative economic organizations with a total population of 1211; The main income of the economy depends on the young crops and the land sales. Now it is mainly for the collective industry to lease dividends and go out to work. The average income of urban residents in Duanzhou District is $30 \%$ lower $^{[3]}$.

Yanqian Village is located in Xianggang Mountain. It is adjacent to the famous National Star Lake Scenic Spot in the north, Dongmen Square in the east and Xinghu Avenue in the south. The whole village is surrounded by mountains and waters, and its location advantage is obvious. It is only 1 kilometer from the city center. In addition, there is the "Guangdong Most Beautiful Greenway”, which is passed through the village. With unique scenery and geographical advantages, such as Yanqian Village, the unique location between the mountains and rivers. Traditional villages are rare in China, have a long history, superior geographical position, rich historical and cultural resources, and are the important research and development value of landscape village. one.

The main street of Yanqian Village, Yanqian Road, is built on the waterfront, and the coastline is twisted and twisted (Fig. 3). The buildings along the waterfront are built by the villagers spontaneously. There is no unified planning, and there is no chaos, which can not highlight the characteristics of Lingnan Jingcun. The villages here are like other villages in the city. The farmers who lost their land mainly rely on housing leases. In recent years, with the development of tourism, some foreign entrepreneurs rented houses, built B\&B hotels, cafes, folk libraries, and creative design companies. Most of the traditional buildings in the village have been demolished. Fortunately, some villagers' ancestral temples have been preserved, and the ancient villages still have their remains.

\section{2 landscape village image positioning}

The image of landscape villagecan be positioned as "the scenery of the water, the leisure garden, the old street of the water street, the strolling of the village", and the first scenic village "Waterfront Street" in Zhaoqing City. The front street is positioned as a pedestrian street, built on the surface of the water, connected with the old lane and the vegetable garden. The lake and the ancient village are intertwined into a scene, creating a "water rhyme style street" with the characteristics of Lingnan landscape village which makes the capital of Jingdu landscape village reappear. At the same time, in combination with the Xinghu Greenway, the Xinghu Scenic Area is built to construct a characteristic leisure commercial corridor with traditional and natural blending, local customs and waterfront sentiment. It provides a rare rural leisure, shopping and sightseeing. Farming and accommodation, experience the route. Through planning, landscape village, which combines rural leisure, cultural tourism, special product sales and residence, which is dominated by the characteristics of Lingnan landscape village, will be transformed into a single "catering economy".

\section{Practice of Landscape Spatial Planning in landscape village}

Yanqian Village sits on the mountain surface water, Xinjie Ancient Lane, and the capital of 
Jingdu Village, just like a pearl on the Star Lake. According to the field investigation, in terms of functional positioning, it is necessary to plan two main streets inside and outside, the lake and the outer street are set up, the inner street and the ancient alley are connected in series, and the old and the old are woven into each other, and the ancient village of Yanqian Village is revived. Depicting a picture of landscape village ${ }^{[5]}$ with water as the keynote, mountain as the body, green as the foundation, and the text as the pulse. Through planning, we will build a Lingnan Village featuring rural tourism, homestay, leisure, recuperation and shopping experience, changing the single economic structure and adapting to the multi-industry linkage economic model. In view of the above situation, the village texture is sorted out, and the pre-rock village is planned as a spatial pattern of one park, two streets, multiple lanes and many scenic spots(fig1).

"one garden" refers to the Xiangshan park, which is 55 meters high and is the highest point of the village in front of rock. It is also one of the eight hills in the scenic spot of Xinghu Lake. The vegetation on the mountain is good, mainly some local tree species, camphor, yellow bark, conformation and so on. There are many ancestral graves and sacrificial places in Xiangshan. ${ }^{\text {[2] }}$ according to the plan, Chengxiang Mountain Park beautifies the original ancestral graves and properly uses plant barriers. Some local productive tree species such as litchi and longan were planted on the base of the original plants, and some parts of the park formed productive landscape micro-village forest park. If Xiangshan Park is completed, it will form an ecological barrier to the village of Ishiya and even the seven stars. The ecological environment of rock scenic area has an important impact on reducing the environmental pollution brought by Xinghu Avenue and improving the regional environmental quality. From the view of landscape, Xiangshan Park is superior in geographical location, located at the highest point of the village in front of rock, and has a wide view of the landscape, which can not only overlook the scenery of Qixing Rock Lake, but also overlook the whole view of the ancient village. In this way, Xiangshan Park and Qixing Rock Scenic spot can be linked to expand the landscape area of Xinghu Lake and form a harmonious relationship between the villages.

he second Street refers to the main Street of the former Rock Village and the Front Road of the Rock Front Village and the Inner Street of the Rock Front Village. Rock front road is nearly 2 kilometers long, planning after completion is a eat, live, travel, purchase as one of the Lingnan characteristic cultural district, sharing the seven star rock scenic spot part of reception function. In the street design layout, according to the existing environment, add block public nodes, so that tourists have time to stop to enjoy the scenery of Qixing Rock Scenic spot. In the height of the building, the highest building does not exceed two stories, paying attention to the harmonious relationship between the building and the street. On the facade design of street building, preserve the characteristics of Lingnan classical architecture as far as possible, green brick and grey tile, inclusive. Let buildings, streets and entire villages Form a unified relationship. The main function of Yanqian Village Street is the residents' life communication, the design is mainly static space, the public rest area of the street is increased, and the interaction between the neighbors is increased. The inner and outer streets are separated and connected properly, which not only keep the villagers' privacy, but also pay attention to the communication between the villagers and the creators, so as to create a harmonious community rest environment.

"multi-lane" mainly according to the geographical and topographic conditions of the village, built in accordance with the mountains. On the basis of the original alleys, the proper increase of alleys is convenient for villagers to enter and exit, forming a multi-lane spatial pattern. This is also the wisdom of the original people living in the village, according to the conditions of the local vein, preserve the unique texture of the village, let the lake, mountain, village, landscape form a whole 
development, mold the characteristic village culture tourism scenery village.

The "multi-scenic spot" refers to the pattern of waterfront construction in Yanqian Village, the creation of many characteristic public spaces, the protection of ancient trees, ancient buildings, ancestral halls and so on, which add ancient rhyme to the villages. Demolish the shantytown building that occupies the road illegal building, pay attention to the small garden construction, grow the plant such as egg flower appropriately, pay attention to the building of rest space under the tree, facilitate the villagers to pull the parents, the villagers and the tourist exchange, form the stable community security relation. This makes the scenic spots small, exquisite and orderly.

"multi-lane" mainly according to the geographical and topographic conditions of the village, built in accordance with the mountains. On the basis of the original alleys, the proper increase of alleys is convenient for villagers to enter and exit, forming a multi-lane spatial pattern. This is also the wisdom of the original people living in the village, according to the conditions of the local vein, preserve the unique texture of the village, let the lake, mountain, village, landscape form a whole development, mold the characteristic village culture tourism scenery village.

The "multi-scenic spot" refers to the pattern of waterfront construction in Yanqian Village, the creation of many characteristic public spaces, the protection of ancient trees, ancient buildings, ancestral halls and so on, which add ancient rhyme to the villages. Demolish the shantytown building that occupies the road illegal building, pay attention to the small garden construction, grow the plant such as egg flower appropriately, pay attention to the building of rest space under the tree, facilitate the villagers to pull the parents, the villagers and the tourist exchange, form the stable community security relation. This makes the scenic spots small, exquisite and orderly.

This kind of village pattern of one garden, two streets, many lanes and many scenic spots makes the village around Xiangshan form the spatial pattern of long street and short lane and waterfront. Not only can let the villagers see the mountain, see the water, but also let Chuankai to live in homesickness, to see the beautiful scenery of the village.
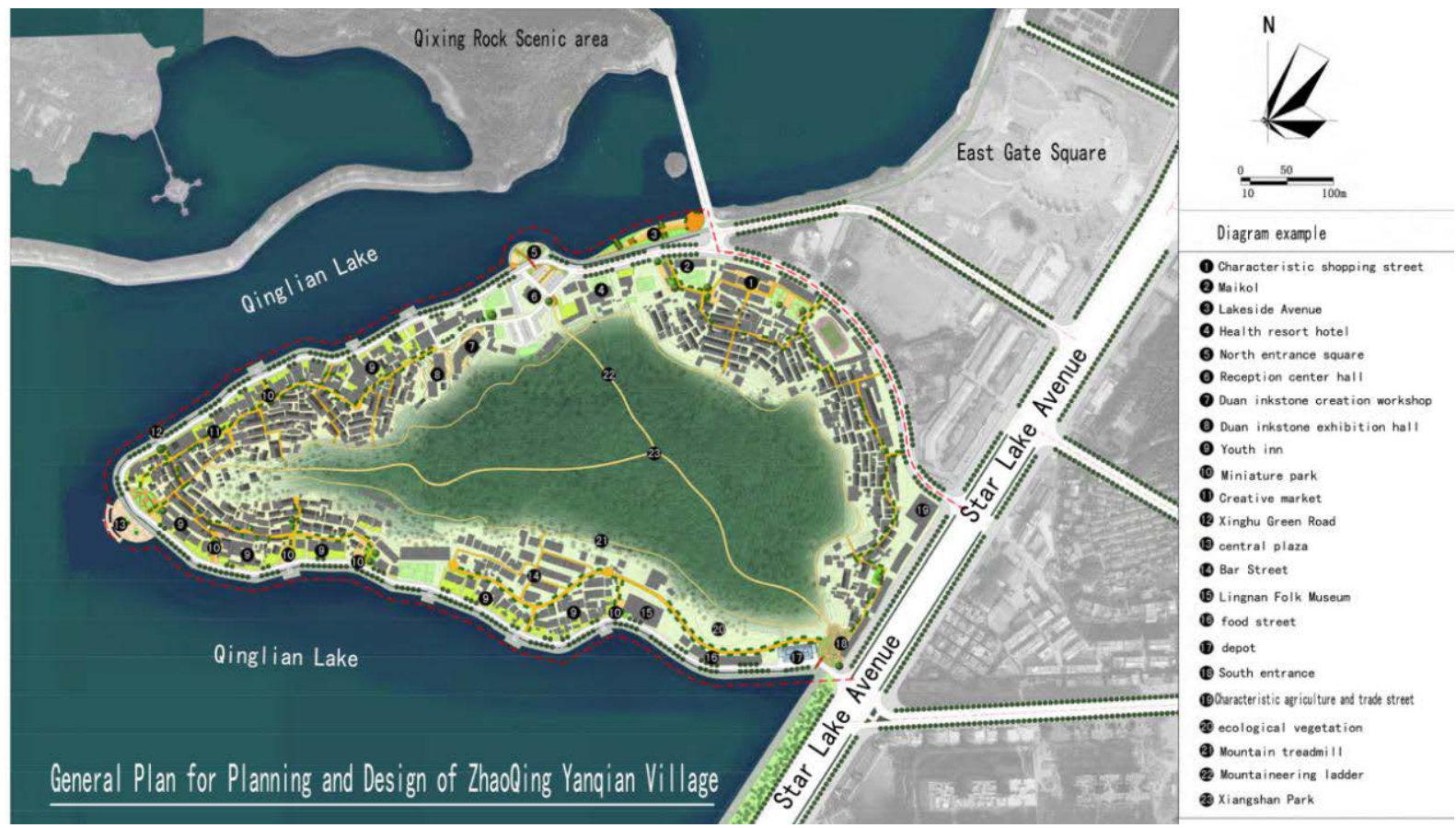

Fig1. General Plan for Planning and Design of ZhaoQing Yanqian Village 


\section{Design innovation point}

\subsection{Government Macro Planning-Guangfu Ecological View Village}

Yanqian Village is located in the surrounding area of Xinghu Lake. According to the "Zhaoqing City Master Plan (2011-2030)", there are clear development guidelines for the district, to create a regional commercial center, a tourist service reception center, and to control the development intensity and building height. It is stipulated that the Yanqian Village shall be uniformly planned by the municipal government, unified land requisition, the adoption of integral transformation, partial demolition, creation of a front vogue street, and long-term overall demolition and relocation. ${ }^{[4]}$ from the Zhaoqing City planning, it can be seen that the Yanqian Village is located in the Qixing Rock Scenic area, Based on the special geographical location of the village, the government has a clear planning guidance. Xinghu ring island green road through the village of rock, Xinghu scenic spot tour Tourism industry led, the emergence of spontaneous sporadic business villagers. Near-term planning, villagers can also participate in the planning of characteristic rock front village construction, long-term is also land demolition. The main duty of the government is to make use of the unique location advantages of the village, to bring into play the characteristics of the green mountains and rivers of the village, and to carry out the construction of the beautiful village of Jingbian village and environmental management.

\subsection{Make Micro Design_—Creating Waterfront Street}

The landscape reconstruction design combined with the present condition and the long-term planning of Yanjian village, the village environment is constructed by "micro-design by stages". Under the condition of not changing the local villagers' way of life, the rural environment should be improved in a suitable way of economy, and the type of village industry should be enriched, and then the overall environment of Yanqian village should be promoted. The food bar, folklore hall, design hall, such as honeycomb, magic cube, edge point, garden, new city, Lianan lake house, small Wu Gui library, etc. For example, the "hive" meal, built in 2014, is designed by creators to use hive elements to transform old buildings. The "Rubik's Cube" food bar, built in 2015, upgraded the original residence, implanted the Rubik's Cube design concept, placed power locomotives in front of the door, and shaped a different Western restaurant. Built in 2016, the "Lianan Lake House" folk custom hotel, known as the most beautiful folklore, was transformed into the most beautiful folk hotel by creators who rented a bankrupt factory building, giving the beautiful scenery of Qinglian Lake a panoramic view. (fig. 2) the involvement of this kind of capital is not a major demolition and construction, but through the micro-design and phased transformation of the village to add new vitality worthy of encouragement. 


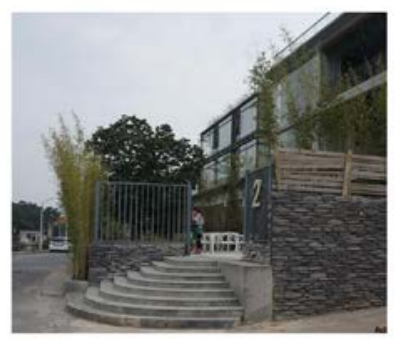

Lianan hotel

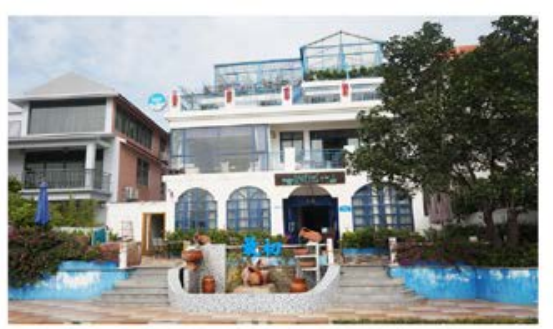

Original restaurant

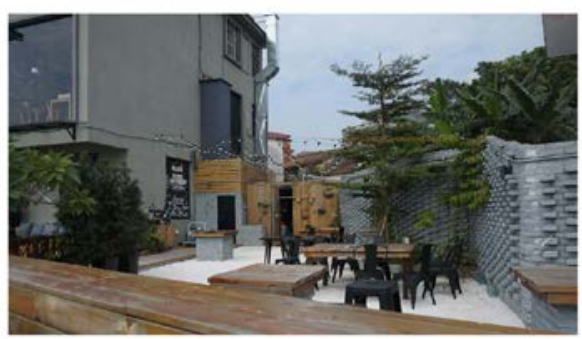

West City Restaurant

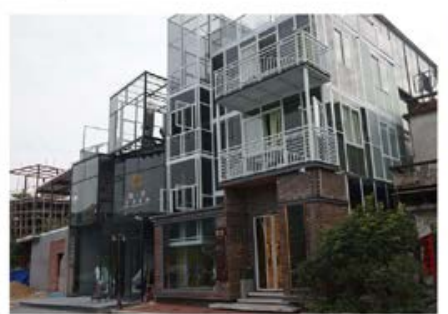

Listening to art space

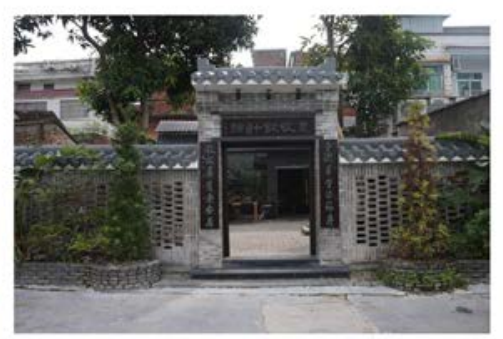

Bumper harvest design building

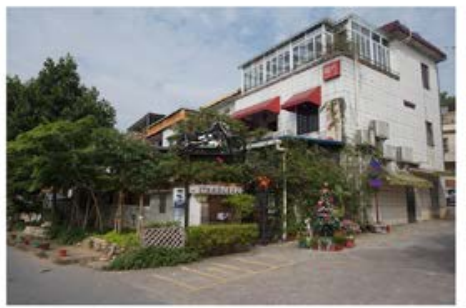

Rubik's Cube.

Fig2 Creators investment bar, design hall, lodging

\subsection{Villagers' participation-inheriting Village Culture}

The main part of the traditional villages living on the edge of the scenic spot is the local villagers. To create a livable new rural landscape, the villagers should be consulted extensively, and the ancient buildings and ancestral halls, arches, centuries-old trees and millennial villages that need to be protected should be defined to determine the village's The industrial landscape and style features avoid the unilateral planning of the government or designers, and the planning designers and villagers jointly complete the village construction. According to the provisions of the Urban and Rural Planning Law, the final planning results of the village must pass the village representative assembly before they can be submitted for approval. The new landscape construction of Yanqian Village must be jointly built by villagers and designers. This planning design attempts to awaken the original strength of Jingcun and restore the self-renewal capacity of Yanqian Village. Under the pattern of respecting the ancient villages in Lingnan in the Ming and Qing Dynasties, we will transform some of the architectural functions, consciously beautify the courtyard space, increase public space, and improve living facilities.

\section{4 diversification-creating a characteristic production scene Village}

Most of the land is leased or expropriated by the government, and only a small amount of land is reserved, according to a survey at Iwamaru. Characteristic production and ornamental landscape construction are the basic strategies to solve the problem. According to the characteristics of "wet water temperature" in Lingnan area, the water quality is dry and hot, and the body is easy to "gather fire", it is necessary to plant Chinese herbal tea, such as egg flower, honeysuckle flower, wild chrysanthemum flower, kapok cotton, summer withered grass and so on. In addition, Xiangshan Park in the original native species, can grow local characteristics of plants, such as longan, litchi, yellow peel, citrus (fruits of Zhaoqing Institute of Fruit Research), to build a harvest garden. Improve traditional flower cultivation techniques, Let traditional rose, camellia, jasmine, lilac and so on to form stumps bonsai, improve economic value. Before and after the construction of flower pool, the residents can interchangeably eat vegetables and local flowers, Rain Water collection garden. In this way, not only can herbal tea crops and flowers earn economic income, but also solve 
the problem of vegetables in the lives of ordinary residents. Of course, these gardens need designers, plant experts and villagers to create a productive landscape with local characteristics.

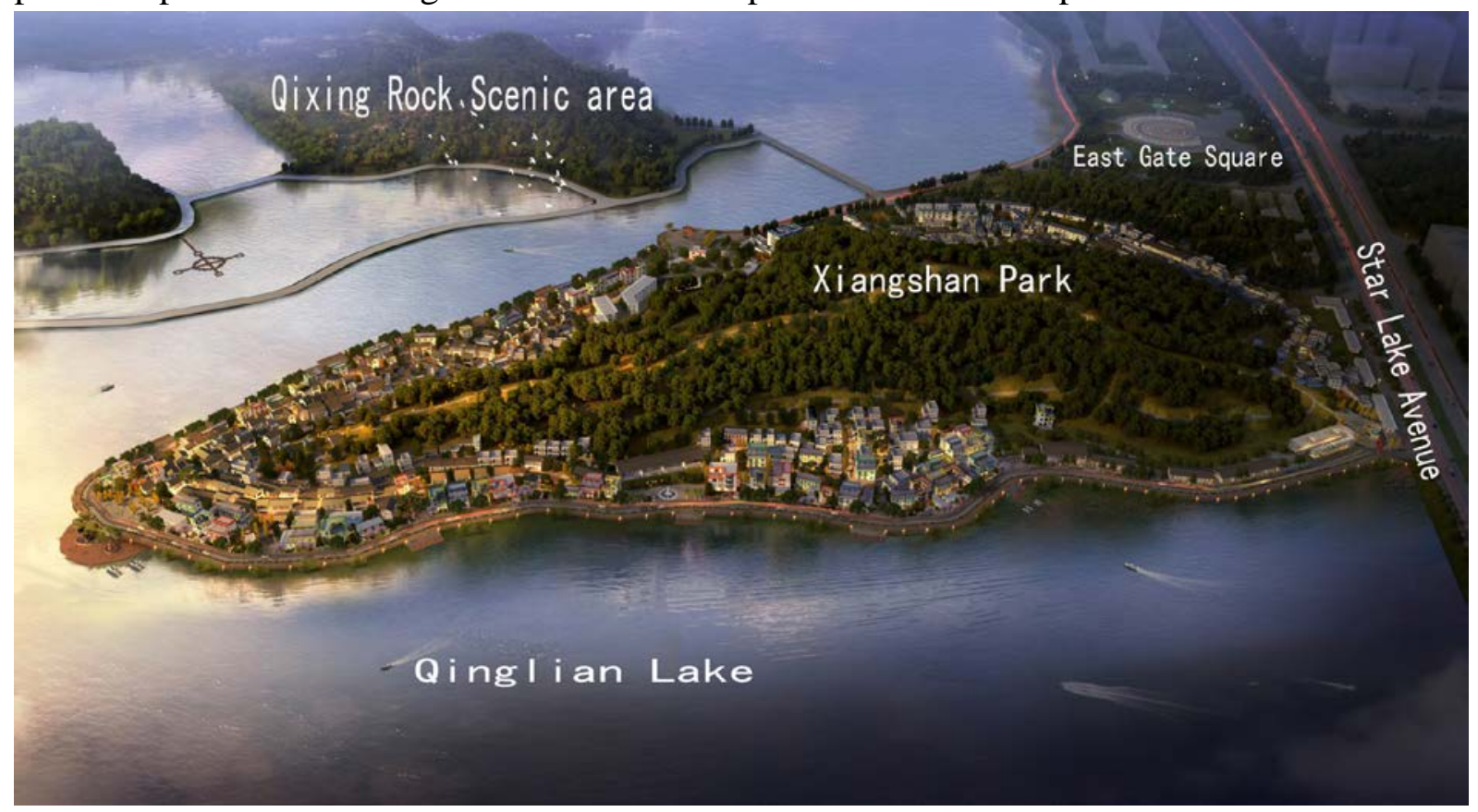

Fig3 Bird 's-eye view azimuth map of rockfront village

\section{6 conclusion}

The main part of the traditional villages living on the edge of the scenic spot is the local villagers. To create a livable new rural landscape, the villagers should be consulted extensively, and the ancient buildings and ancestral halls, arches, centuries-old trees and millennial villages that need to be protected should be defined to determine the village's The industrial landscape and style features avoid the unilateral planning of the government or designers, and the planning designers and villagers jointly complete the village construction. According to the provisions of the Urban and Rural Planning Law, the final planning results of the village must pass the village representative assembly before they can be submitted for approval. The new landscape construction of Yanqian Village must be jointly built by villagers and designers. This planning design attempts to awaken the original strength of Jingcun and restore the self-renewal capacity of Yanqian Village. Under the pattern of respecting the ancient villages in Lingnan in the Ming and Qing Dynasties, we will transform some of the architectural functions, consciously beautify the courtyard space, increase public space, and improve living facilities.

In the process of landscape planning and design of Yanqian Yanqian Village, according to the geographical relationship of the rock front and the spatial structure of the village, the spatial pattern of one park, two streets, multiple lanes and many scenic spots was planned. This kind of stringing is a line, with a line to face, to promote the overall planning way, not only to solve the living environment suitable for the modern lifestyle of the villagers, but also to undertake part of the tourist reception function of the Qixingyan Scenic Area, to create a humanistic care feature. Tourist-friendly village. Adjust the industrial structure, create a new productive landscape, change the single economic structure model, and create a Jingcun resort resort with multi-industry linkage economic development.

The construction of rural landscapes at the edge of cities and scenic spots is a valuable topic. How do these marginal landscapes develop in a benign manner while maintaining their own characteristics in the process of urbanization,22enhance their own landscape quality, form a 
symbiosis with the mountains, coexist with the water, and share with the green The melting peach blossom style of Jingcun. This kind of "government guidance + maker capital + landscape planner + villagers" is the joint intervention, and the new rural development model at the edge of the development of multi-industry linkage is worth looking forward to.

\section{References}

[1] Xiong Kai. Rural Image and Rural Tourism Development [J]. Journal of Guilin College of Tourism 1999 (3): $70-73$. [2]Zhu Chun, Zhang Yuanhuan, Hong Shuyuan. To carry forward the ancient village culture: to highlight the features of the beautiful rural areas [J]. Guangdong Gardens, 2015, (2): 4-7.

[3]Shan Yan name, Zhao Tianyu, Zhang Gao Pan. A study on the Cultural inheritance Model based on Humanistic solicitude-the Enlightenment of the Community Building in Taiwan to the Protection of Historical villages and towns [J]. Chinese Gardens, 2016, (6): 11-14.

[4]Zhaoqing Urban and Rural Planning Bureau. Village renovation Planning of Yanqian Village, Duanzhou District, Zhaoqing City [R]. Zhaoqing: Zhaoqing Urban and Rural Planning Bureau, 2016.

[5]Meng Kunling, Lu Xiaojun. Analysis on the Design method of systematic Construction of Beautiful Countryside Taking the practice of Yangshan Town in Wuxi as an example [J]. Adornment: 2017, (04): 90-92.

[6]Dai Songqing. "Yancheng Ancient Street" Rural Landscape Planning and Design in the suburbs of Fan GE Zhuang, Yanqi Town, Beijing [J]. Chinese Gardens, 2016, (1): 28-31.

[7]Xu Wenhui, Tang Lizhou. Study on the "four Yi" Strategies in the Planning and Construction of Beautiful Countryside [J]. Chinese garden: 2016, (9): 20-23. 